Studia Slavica Savariensia 2018. 1-2. 162-169

DOI: $10.17668 / \mathrm{SSS} .2018 .1-2.162$

\author{
Molnár Angelika ${ }^{1}$ \\ (Debrecen, Magyarország)
}

\title{
АЛЛЕГОРИЗАЦИЯ У ТУРГЕНЕВА И ВЕН. ЕРОФЕЕВА
}

\begin{abstract}
This paper studies the allegory techniques in Ivan Turgenev's short story "The First Love" and in Venedikt Erofeev's "Notes of a Psychopath". The analysis looks upon the varieties of characters, the ways of their function in prose texts. Turgenev rethinks the existing forms, Erofeev, who redefines the literary language, makes them visible and thus destructs them. The analysis of methods and forms of allegories demonstrates a typical $19^{\text {th }}$-century technique, and foreshadow a characteristic trend in its usage at the end of the $20^{\text {th }}$ century. Our approach manifests the forms of remaking allegories in the classical and the post-modernist literature.
\end{abstract}

Keywords: "The First Love", "Notes of a Psychopath", allegory, metaphors, characters, birds

В повести И. С. Тургенева «Первая любовь» приводятся второстепенные персонажи: поклонники Зинаиды Засекиной. Они обычно отодвигаются на второй план, так как в интерпретации текста выдвигаются совершенно другие аспекты (см. БАТЮТО 1972; ПУСТОВОЙТ 1987; ШАТАЛОВ 1979; NITZSCHMANN 2016). Поэтическую функцию таких лиц можно объяснить как оппозицию главным героям: показать необычный характер последних на фоне первых. Кроме того, если все они и не выполняют роль развития интриги, то, по крайней мере, участвуют в главном конфликте повести. На наш взгляд, образ поклонников основывается на аллегоризации, т.е. на однозначном замещении, в отличие от особой поэтизации образов Зинаиды, отца и Владимира Петровича, которые представляются с помощью многозначной метафоризации. Настоящим представляется мотивировка иносказательной функции этих персонажей.

Автор тетрадки называет сборище поклонников Зинаиды как «цыганский табор», потому что у них подчеркнуто веселое и буйное расположение духа: «и на фортепьяно играли, и пели, и танцевали», «старика Вонифатия нарядили в чепец, а княжна надела мужскую шляпу...» (ТУРГЕНЕВ 1981: 321). Этот элемент беспечности и издевательства над мужчинами, когда женщина надевает на себя

\footnotetext{
${ }^{1}$ ORCID ID: https://orcid.org/0000-0001-7896-1480
} 
мужскую шляпу, перевоплощаясь в доминантного члена взаимоотношений, определяется в рассказе как «цыганский». Он исчезает, когда Зинаида влюбляется: фанты играются уже «без прежних странных выходок» героини (ТУРГЕНЕВ 1981: 343). В общем, поклонники представляют собой покорных подданных их властительницы: они как собачонки или игрушки в руках Зинаиды «и она их всех держала на привязи, у своих ног» (ТУРГЕНЕВ 1981: 326). Они же вслед друг за другом дежурят у нее, когда она заболевает от любви. Каждый из поклонников в отдельности репрезентирует особую сферу жизни: военную, творческую, научную, светскую и т.д. Именно в этом и проявляется их аллегорическая функция. Однако, как выясняется, ни один из них не может быть подходящей парой для Зинаиды, так как ни один из них не исключителен и не поэтичен, и не подлежит метафорического воспроизведения в тексте Тургенева.

Беловзоров. Воин. Беловзоров ведет себя по-военному, что обозначается его атрибутами (его сабля звенит, он щелкает шпорами). Внешность гусара является слишком стереотипичной и светлой: он «белокурый и курчавый молодец» (ТУРГЕНЕВ 1981: 313). Белый цвет в связи с его образом сменяется на красный (румяное лицо, кровавые глаза), и чистота взора, скрытого в фамилии героя, легко затуманивается. Он очень ревнив: «сидел угрюмо в углу, весь застегнутый и красный» (ТУРГЕНЕВ 1981: 340), готов на физическое насилие: «глаза его наливались кровью», «краснел, и казалось ... сейчас ринется на всех нас» (ТУРГЕНЕВ 1981: 321). По этим характеристикам и справедливо называет его героиня своим «зверем». В его характере ничего большего не скрывается, по этой причине Зинаида и определяет его одним словом: «воин». Однако он готов дать молодому Владимиру Петровичу деньги за выигрышный билет, унижая этим достоинство героини. Он наиболее близок к подростку в соперничестве за Зинаиду, так как он тоже «охотно кинулся бы за нее в огонь» (ТУРГЕНЕВ 1981: 326). И готов жениться на ней, однако после любовной истории Зинаиды, не известно, предлагает ли ей очистить свое запятнанное имя, так как он уезжает на Кавказ, верную смерть. Итак, эта фигура выполняет функцию «воина-ревнивца» рядом с Зинаидой и воплощает такую сторону любви (подростка).

Лушин. Доктор представляет собой медицину, человека, призвание которого лечить больных, а не убивать людей. В отличие от «воина», однако, он является «темневатой» фигурой, «черномазым» господином. Он «насмешливый, цинический на словах» (ТУРГЕНЕВ 1981: 327), однако любит Зинаиду больше всех остальных поклонников. В его отношении, так как «он у ней в руках», она более сильно проявляет свою власть и садизм, протыкая булавку в его же руку. Доктору очень больно, однако он смеется буквально так, как Зинаида это предсказывает. Героиня и в этом деле только примеряет себе роль - роль мучительницы: «Я 
кокетка, я без сердца, я актерская натура» (ТУРГЕНЕВ 1981: 327). Эти самоопределения однако отнюдь не реализуются.

Молодой Владимир Петрович угадывает внутреннюю доброту и любезность доктора, поэтому его и влечет к нему. Как он, так и Зинаида ценит в докторе правдивость: «Я его любил за его прямой и нелицемерный нрав» (ТУРГЕНЕВ 1981: 327). В этом реализуется значение имени персонажа: если «лущить» с доктора напускной цинизм, он оказывается глубоким человеком. Когда окончив университет, юноша словно вылечивается из болезни любви, Лушин это определяет последующему, отрицая любовь, как дрянь и статус, подобный собаке: «Человеком смотрите, не комнатной собачкой» (ТУРГЕНЕВ 1981: 357). Врач выступает в роли наставника подростка, который дает полезные советы. В его толковании любовь также поучительный «урок», «ловушка», и Владимир Петрович может быть счастлив, что вовремя освободился от этих уз: «вся штука оттого, что не умеют вовремя расстаться, разорвать сети.» (ТУРГЕНЕВ 1981: 357). Ирония же врача превращается в раздражительность, цинизм и злость по мере усиления его чувства безответной любви. Однако ни себя, ни Зинаиду вылечить от любви он не умеет. Он представляет собой любовь как болезнь и вечную преданность.

Майданов. Поэт в повести Тургенева представляет собой бесталанный и базарный тип. Наружность его, как и его произведения, типично романтическая и шаблонная: «молодому человеку с худощавым лицом, маленькими слепыми главками и чрезвычайно длинными черными волосами» (ТУРГЕНЕВ 1981: 319). Его поведение - излишне восторженное, вместе с тем и унылое - скрывает, как это успевают заметить и Владимир Петрович, и Зинаида - холодность: «человек довольно холодный, как почти все сочинители» (ТУРГЕНЕВ 1981: 327). Героине он нужен, потому что Майданов отвечает «поэтическим струнам ее души» (ТУРГЕНЕВ 1981: 327), однако она более чутка к настоящей поэзии, поэтому и советует ему читать Пушкина и не декламировать недостойных стихов. Как и все подражатели романтиков, «он ее обожает, воспевал ее в нескончаемых стихах и читал их ей с каким-то и неестественным и искренним восторгом» (ТУРГЕНЕВ 1981: 327). А также, он слишком предсказанно и явно женится и поступает на службу, на которой он «так же ненужно восторгался и так же внезапно падал духом» (ТУРГЕНЕВ 1981: 362). Он не достоин ни Зинаиды, ни того, чтобы воспевать ее. Поэт же - аллегория мечтательности. Здесь также наблюдается контраст с отцом Владимира Петровича: кроме него ни один из поклонников, даже поэт-романтик, не умирает от любви.

Нирмацкий. Шут. Отставной капитан является настоящим рабом, вещью Зинаиды. Он настолько безобразен (рябой, курчавый, сутуловатый, кривоногий), что над ним Зинаида только тешится: она проявляет свою власть, становясь на него как на постамент: «и она в 
пьедестал себе выбрала безобразного Нирмацкого, велела ему лечь ничком, да еще уткнуть лицо в грудь» (ТУРГЕНЕВ 1981: 320). Кроме его внешности и издевательств над ним больше о нем и не говорится: «Нирмацкого одели медведем и напоили водою с солью» (ТУРГЕНЕВ 1981: 321).

Малевский. Злодей. Граф - злой уже по потенциальному значению его фамилии: см. корень *мал. Детализуется внешность графа, говорящего с легким польским акцентом: посредством описания его наружности - он «очень красивый и щегольски одетый брюнет, с выразительными карими глазами, узким белым носиком и тонкими усиками над крошечным ртом» (ТУРГЕНЕВ 1981: 319) - разоблачается установка на показ и внутренняя испорченность характера. Зинаида видит его насквозь и несмотря на ее оговорок (хваление его «усиков»), она не поддается ни его приятной наружности, ни его льстивой речи: «шептать ей на ухо с самодовольной и заискивающей улыбочкой» (ТУРГЕНЕВ 1981: 327). Героиня утверждает, что она таких любить не может, на которых ей «приходится глядеть сверху вниз» (ТУРГЕНЕВ 1981: 328). Ему удается втереться только в доверие княгини и матери Владимира Петровича. Однако и он попадает под власть Зинаиды и являет собой пошлые стороны поклонения.

Лживость, злость и умение играть с другими отталкивает и подростка от него: граф «имел репутацию отличного мистификатора и славился своим умением дурачить людей на маскарадах» (ТУРГЕНЕВ 1981: 349). Однако герой еще не умеет раскусить Малевского полностью: «Граф Малевский втайне казался мне опаснее других. Моя наблюдательность не видала дальше своего носа» (ТУРГЕНЕВ 1981: 331). Своей злой заметкой Малевский усиливает ревность подростка: «слово протекло ядом по всем моим жилам» (ТУРГЕНЕВ 1981: 349). Владимир Петрович как автор тетрадки уже разоблачает как свое прежнее поведение, так и неясное понимание ситуации. Белозворов тоже ревнует Зинаиду графу. Он уподобляется волку, который хочет съесть «увертливого» графа-барана: «как волк на барана» (ТУРГЕНЕВ 1981: 336). Сказочный подтекст реализуется и в других сравнениях: граф движется, «хитро покачиваясь, как лиса», он «ловок и умен, но что-то сомнительное, что-то фальшивое чудилось в нем» (ТУРГЕНЕВ 1981: 327).

Малевский умеет выполнять разные карточные фокусы, однако играет не порядочно: он «сдал себе в вист все козыри» (ТУРГЕНЕВ 1981: 321). Граф точно так же поступает и в связи с анонимным письмом, в котором он ставит жену отца в известность об отношениях отца и Зинаиды, но на самом деле он подкладывает свинью себе, ибо отец об этом говорит ему: «Мне ваш почерк не нравится» (ТУРГЕНЕВ 1981: 355). И как Зинаида выпровождает графа, обидевшего подростка, так и отец Владимира Петровича поступает с ним грозно, выводя его под руку и уничтожая его своими «холодными» словами: «в одном доме указали на дверь»; «если 
вы еще раз пожалуете ко мне, то я вас выброшу в окошко» (ТУРГЕНЕВ 1981: 355).

Итак, несмотря на то, что повесть Тургенева имеет автобиографическую основу, аллегорическое преподнесение второстепенных персонажей у него действует как неявный поэтический прием, противопоставленный метафоризации образов главных героев, как более глубокой формы достижения поэтического эффекта.

В следующей части нашей статьи нам предстоит показать поэтический прием аллегоризации, используемый Венедиктом Ерофеевым в тексте «Записок психопата» в более чистом, упрощенном и явном виде. Аллегория здесь отсылает к историческим событиям, поэтому и становится дидактической. Этот прием можно причислить и к другим поэтическим средствам текста, помимо приема ретардации, о котором пишет Смирнова (СМИРНОВА 2008).

ПТИЦЫ. Запись 1 октября является блестящей аллегорией Ерофеева на коммунистический строй и на трудовой коллектив в образе птиц. В данном фрагменте многожанрового текста (ЕРОФЕЕВ 2004: 193-200) цитируются и известные пословицы, поговорки и песни о птицах, кроме того пародийно употребляются разные идеологизмы (см. напр. «интернационально улыбаться») и т.д. «Птичий остров» представляет собой Советский Союз. Субъекту аллегории, определяющему себя «просвещенным человеком» здесь не хватает «соловьиного пения», т.е. поэтического слова. Становятся известными причины исчезновения такого слова. Из птичьего сбора выделяется пингвин, из приветственной речи которого герой узнает историю острова, а также попугаи, всегда повторяющие произнесенное. Зимнее время сопровождает траурные дни похоронения Удода, который может олицетворять Ленина. На его смену приходит Горный Орел - Сталин, действие которого выражается следующей саркастической фразой: «пернатые впервые почувствовали на своих головах освежающее прикосновение орлиных ногтей» (ЕРОФЕЕВ 2004: 194). Двуглавый орел, символ былой царской власти, также упоминается здесь в противопоставлении с действующим режимом. Известная поговорка о счастье человека («птица создана для полета...»), как главная проблема классической литературы, определяется как выражение «скепсиса» (см. столкновение счастья и долга).

Перефразируются известные события советской истории, в том числе и «культурный переворот». Упоминается смерть известных личностей этой эпохи. Как известно, под псевдонимом «Буревестник» скрывается Максим Горький не только в действительности, но и в аллегорическом тексте Ерофеева. Пока еще не удалось установить точно, кто скрывается под «Фениксом», возможно, это «Феликс» Дзержинский, но образ возрождающейся птицы потенциально скрывает как известного политического деятеля, так и деятеля культуры. Отмечается исторически реально существующая кампания против оппозиционеров («кур»). Травля 
в ерофеевском тексте получает определение опять же по поговорке: «Курица не птица...».

Операции со звуком «р», пронизывающие текст в целом, имеют место и в этом фрагменте. Дупликация «р» окрашивает, в первую очередь, звукоподражание птиц: «Вороны ... карр-кали»» «петушки ку-карр-екали» (ЕРОФЕЕВ 2004: 194). Такая форма разноголосого общения птиц раньше считалась нормальной, однако после смены режима все изменяется. Издание конституции объясняется сатирически, как результат угрызений Орла (Сталина) из-за репрессий. Излагается суть этой конституции, в которой легко обнаруживается профанация оригинала: все имущество государства общее; воробьи, т.е. пролетариат провозглашается единственным классом, и их слово «чик-чирик»- единственным словом, т.е. запрещается свобода мнений и вводится «семейная» диктатура.

Нападение со стороны хищных птиц (ястребов, - указание на страусов является усилением пародийности) может отсылать к реальным войнам, однако образ врага переносится с внешнего на внутренний. Получается двойная угроза. Это акцентируется на уровне высказывания путем умножения «р»: «Ворроны накарркали!!», «злые корршуны», «черрные когти!» (ЕРОФЕЕВ 2004: 196). В речи Орла, побуждающей к самообороне, воробьи уже возвышаются до соколов. Приводится еще одна фразема, содержащая «птичий текст»: «Ни пуха вам, ни пера!». Кроме того, перефразированно воспроизводятся как известные песенки о полете, так и боевые призывы в подобном контексте: «Дадим им дрозда!». Пародийное снижение фраз обозначается и в виде развертывания «р»: песня «Крови жаждет сизокрылий голубок» сокращается до звука карканья: «Кррр!», а смысл фразы уже сам по себе является оксюмороном. Насильно преувеличенный боевой дух выражен сходными смысловыми парадоксами: «сраженный воробей», «жареный лед», «птичье молоко» (ЕРОФЕЕВ 2004: 196).

Ласкательные обращения влюбленных, характерные для людей, в записи переносятся на птичий мир: «касатик», «ласточка». Помимо других реализованных фразем, акцентируются и «красные петухи» (см. огонь). Парадоксально звучит также «воробьиная песня»: «Салавей, салавей» (ЕРОФЕЕВ 2004: 197), не говоря уже об орфографии слова, отражающей устное произношение. Субъектом аллегории пародийно осуждается идея следующей кампании: Орел как бы путает значения иностранных слов «ре-» и «де-» милитаризации. В игре слов горько высмеивается и последующая репрессия («поскрипционный список»): слово «чик-чирик» становится равнозначным «пиф-паф» в значении убийств. Это может направить внимание читателя на новое смыслопорождение. Вместо аллегоризации исторических событий, следует искать смысл в развертывании слова. Единоголосие равнозначно смерти, поэтому и требуется отход от него к многоголосию для выработки творческого отношения к вербализации мира. Такое 
преодоление может вызвать и аллюзия на детский фильм «Гибель Орла», которая перефразируется как «Смерть Вождя», олицетворяющего смерть властного слова.

С этой точки зрения детализуется и функция «пингвина»- по всей вероятности, Н. Хрущева -, так как «навоз экономического развития» и термин «оттепель» отсылает к его времени. Слово «оттепель» снова выворачивается Ерофеевым на изнанку, как почва для продвижения, а для субъекта текста - к иному слову: «гололедица, как известно, лучшая почва для "поступательного движения вперед"» (ЕРОФЕЕВ 2004: 198). «Черные вороны» могут подразумевать черные Волги, увозящие представителей т.н. «молодого поколения», которые критиковали первого секретаря - «бестолкового пингвина» - за его глупые постановления и необразованность. Двойственность объявления миролюбивой внешней политики также обнажается («голуби» - «ястребки») (ЕРОФЕЕВ 2004: 199).

Субъект аллегории называет себя представителем «подводного царства», т.е. пространства смертельного и противопоставленного небесному миру. Однако в качестве гостя «Птичьего острова» герой утверждает свое дружественное отношение и вводит в свою речь как ссылку на «Чайку» Чехова, так и фразеологизмы: «как рыба в воде» и «молчать, как рыба». В этом можно усмотреть и пародию на дипломатические речи представителей дружеских государств, социалистических стран. Герой наконец-то будто услышит песнь соловья, однако впечатление разрушается при упоминании кала, говорящего «о подъеме материального благосостояния» (ЕРОФЕЕВ 2004: 199). Пародийное соединение высокого и низкого обозначает неадекватное слово и получает свое развитие в утверждении «все эти звуки и запахи сливаются в одно - в мелодию "лебединой песни"» (ЕРОФЕЕВ 2004: 199). Лебединая песня звучит для прощания с идеологическим словом. Этим и обрывается аллегория-фрагмент.

В записи от 10 октября данная тема будто продолжается, однако, так как подлежащее полностью отсутствует из предложений, не ясно, кто «Проносятся, взбираются ... к зениту» (ЕРОФЕЕВ 2004: 200). Возможно, это - звуки или птицы или же мысли субъекта дневника. 11 октября также действует особая поэтизация текста: дням недели синестетически присваиваются разные цвета. 12 октября субъект письма ищет отговорки по причине своего опоздания на встречу с уезжающей любовницей. Он утверждает, что «совсем не сошел с ума» (ЕРОФЕЕВ 2004: 201). однако отказывает участвовать в чувствительной сцене прощания. Здесь опять имеются отсылки на образы птиц: герой должен доказать, что «жаворонок» еще «умеет играть», но в конце концов он приходит к выводу, что «нужно быть сумасшедшим» (ЕРОФЕЕВ 2004: 201).

Таким образом, единственная поющая (любящая) птица представляет собой «психопата», противопоставляется диктаторскому, властному 
единоголосию режима. Сумасшествие означает разработку нового языка для воспроизведения действительности субъектом текста. Аллегория деконструируется и обрастает более широким смысловым диапазоном.

\section{Литература}

БАТЮТО 1972 = БАТЮТО А.И. Тургенев-романист. Москва, 1972.

ЕРОФЕЕВ 2004 = ЕРОФЕЕВ В.В. Записки психопата. (ред., комм. А.Е. Яблоков) Москва, Захаров, 2004.

ПУСТОВОЙТ 1987 = ПУСТОВОЙТ П.Г. И.С. Тургенев - художник слова. Москва, 1987.

СМИРНОВА 2008 = СМИРНОВА Е.Е. Реализация приема ретардации в «Записках психопата» Вен. Ерофеева // Вестник КГУ им. Н.А. Некрасова. 2008. № 1. C. 138-139.

ТУРГЕНЕВ 1981 = ТУРГЕНЕВ И.С. Первая любовь // Тургенев И.С. Полн. собр. соч. и писем: В 30 т. Соч.: В 12 т. Москва, 1981.

ШАТАЛОВ 1979 = ШАТАЛОВ С.Е. Художественный мир И. С. Тургенева. Москва, 1979.

NITZSCHMANN $2016=$ NITZSCHMANN K. Erste Liebe - letzte Liebe? Zur Erzählung Este Liebe von Iwan S. Turgenjew (1860) // К Тургеневу в БаденБаден: сборник материалов международных научных конференций [20132014] (редкол. М.Б. Лоскутникова и др.) Москва, Экон-информ, 2016. 54-66. 